\title{
Hedgehog signalling in myeloid cells impacts on body weight, adipose tissue inflammation and glucose metabolism
}

\author{
Julia Braune $^{1}$ - Ulrike Weyer ${ }^{1} \cdot$ Madlen Matz-Soja $^{2}$ - Constance Hobusch ${ }^{1}$. \\ Matthias Kern $^{3}$ • Anne Kunath ${ }^{4}$ Nora Klöting ${ }^{4}$ • Susann Kralisch ${ }^{5}$ • Matthias Blüher ${ }^{5}$. \\ Rolf Gebhardt $^{2} \cdot$ Yana Zavros $^{6}$ • Ingo Bechmann ${ }^{1} \cdot$ Martin Gericke $^{1}$
}

Received: 13 December 2016/Accepted: 23 January 2017 /Published online: 23 February 2017

(C) Springer-Verlag Berlin Heidelberg 2017

\begin{abstract}
Aims/hypothesis Recently, hedgehog (Hh) was identified as a crucial player in adipose tissue development and energy expenditure. Therefore, we tested whether Hh ligands are regulated in obesity. Further, we aimed at identifying potential target cells of Hh signalling and studied the functional impact of Hh signalling on adipose tissue inflammation and glucose metabolism.

Methods Hh ligands and receptors were analysed in adipose tissue or serum from lean and obese mice as well as in humans. To study the impact on adipose tissue inflammation and glucose metabolism, Hh signalling was specifically blocked in myeloid cells using a conditional knockout approach (Lys-Smo ${ }^{-/}$).

Results Desert Hh (DHH) and Indian $\mathrm{Hh}(\mathrm{IHH})$ are local $\mathrm{Hh}$ ligands, whereas Sonic $\mathrm{Hh}$ is not expressed in adipose tissue
\end{abstract}

Julia Braune and Ulrike Weyer contributed equally to this work.

Electronic supplementary material The online version of this article (doi:10.1007/s00125-017-4223-5) contains peer-reviewed but unedited supplementary material, which is available to authorised users.

Martin Gericke

martin.gericke@medizin.uni-leipzig.de

1 Institute of Anatomy, Leipzig University, Oststrasse 25, D-04317 Leipzig, Germany

2 Institute of Biochemistry, Faculty of Medicine, Leipzig University, Leipzig, Germany

3 German Center of Diabetes Research (DZD), Leipzig, Germany

4 IFB Adiposity Disease, Core Unit, Leipzig University, Leipzig, Germany

5 Department of Medicine, Leipzig University, Leipzig, Germany

6 Department of Molecular and Cellular Physiology, University of Cincinnati, Cincinnati, USA from mice or humans. In mice, obesity leads to a preferential upregulation of Hh ligands $(D h h)$ and signalling components (Ptch1, Smo and Glil) in subcutaneous adipose tissue. Further, adipose tissue macrophages are Hh target cells owing to the expression of Hh receptors, such as Patched 1 and 2. Conditional knockout of Smo (which encodes Smoothened, a mandatory $\mathrm{Hh}$ signalling component) in myeloid cells increases body weight and adipose tissue inflammation and attenuates glucose tolerance, suggesting an anti-inflammatory effect of Hh signalling. In humans, adipose tissue expression of $\mathrm{DHH}$ and serum IHH decrease with obesity and type 2 diabetes, which might be explained by the intake of metformin. Interestingly, metformin reduced $D h h$ and $I h h$ expression in mouse adipose tissue explants.

Conclusions/interpretation Hh signalling in myeloid cells affects adipose tissue inflammation and glucose metabolism and may be a potential target to treat type 2 diabetes.

Keywords Adipose tissue - Diabetes · Glucose tolerance · Hedgehog · Inflammation · Macrophages · Obesity $\cdot$ Smo

$\begin{array}{ll}\text { Abbreviations } \\ \text { ATM } & \text { Adipose tissue macrophage } \\ \text { BAT } & \text { Brown adipose tissue } \\ \text { CLS } & \text { Crown-like structures } \\ \text { CT } & \text { Computed tomography } \\ \text { DHH } & \text { Desert hedgehog } \\ \text { FPI } & \text { Fasting plasma insulin } \\ \text { FPG } & \text { Fasting plasma glucose } \\ \text { HFD } & \text { High-fat diet } \\ \text { Hh } & \text { Hedgehog } \\ \text { HHAT } & \text { Hedgehog acyltransferase } \\ \text { IB4 } & \text { Isolectin B4 } \\ \text { IHH } & \text { Indian hedgehog }\end{array}$


SHH Sonic hedgehog

SMO Smoothened

WAT White adipose tissue

\section{Introduction}

One of the major health problems in Western societies is an unbalanced energy metabolism, which increases the risk of obesity and associated pathologies including hypertension, coronary heart disease, stroke, several types of cancer and type 2 diabetes [1]. Obesity is associated with a chronic low-grade inflammation within adipose tissue and an increase in immune cells, specifically macrophages [2-4]. Adipose tissue macrophages (ATMs) accumulate around dying adipocytes and generate characteristic crown-like structures (CLS). In addition, the immune phenotype of ATMs in obesity shifts from an alternatively activated (M2) to a classically activated (M1) phenotype [5]. M1 macrophages secrete proinflammatory cytokines, such as IL-1 $\beta$ or TNF $\alpha$ [6], and are therefore referred to as proinflammatory macrophages. Importantly, infiltration of ATMs is the strongest independent predictor of insulin resistance. Moreover, adipose tissue inflammation strongly correlates with hepatosteatosis $[7,8]$.

In 1980, Nüsslein-Volhard and Wieschaus discovered the evolutionarily conserved hedgehog $(H h)$ gene [9]. Since then, Hh has been implicated in many fundamental processes in embryo development including cell growth, survival, fate and patterning [10] as well as in maintenance of adult stem cell niches [11]. Furthermore, dysregulation of Hh signalling contributes to various pathologies, most notably different kinds of cancers [12], developmental disorders [13] and human syndromes, such as BardetBiedl syndrome [14].

After binding of Hh ligands, the inhibitory association of the Patched receptor with its co-receptor Smoothened (SMO) is removed. Subsequently, GLI (GLI-Kruppel family member GLI1) transcription factors translocate to the nucleus and modulate specific target genes. Hh family ligands, including Sonic (SHH), Indian (IHH) and Desert hedgehog (DHH) require autoprocessive cleavage as well as post-translational modifications. In this context, the hedgehog acyltransferase (HHAT) is responsible for palmitoylation and subsequent secretion of $\mathrm{Hh}[15,16]$.

Hh signalling has recently been implicated in adipose tissue regulation [17-19]. For instance, adipocyte differentiation is inhibited in vitro and in vivo by $\mathrm{Hh}$ signalling $[17,18]$. Hh represents a crucial element in adipose tissue development in mammals as fat specific Hh activation in mice led to a total loss of white (WAT), but not brown adipose tissue (BAT). Thus, WAT and BAT adipogenesis are differentially regulated by $\mathrm{Hh}$ [18]. Further, Hh signalling reprograms cellular metabolism toward a Warburg-like glycolytic state via an additional, non-canonical Hh signalling pathway [20]. In humans, the impact of dysfunctional $\mathrm{Hh}$ signalling is further displayed in the genetic disorder Bardet-Biedl syndrome, which is characterised by defects in multiple organ systems, truncal obesity and diabetes [21].

The present study aimed to explore the regulation of $\mathrm{Hh}$ ligands and its signalling components in obesity. Our hypothesis is that dysregulation of Hh ligands could contribute to obesity-associated diseases, such as type 2 diabetes. Further, we aimed at identifying Hh target cells within adipose tissue to unravel an additional mechanism linking Hh dysregulation in obesity to type 2 diabetes.

\section{Methods}

Experimental animals Mice were maintained in the local animal facility with a $12 \mathrm{~h}$ light and dark cycle and with free access to food and water. For diet-induced obesity, male wild-type C57BL/6 J mice (from the animal facility at Leipzig University) were fed a high-fat diet (HFD; 60\% energy from fat; Ssniff-Spezialdiäten; Soest, Germany) for 20 weeks, starting at 6 weeks of age. Control littermates were kept on a regular chow diet. Group assignment was blinded to the investigator. In addition, we used a transgene mouse model expressing a myeloid cell-specific deletion of the Smo gene, which encodes the hedgehog co-receptor SMO, generated and characterized by Y. Zavros (Department of Molecular and Cellular Physiology, University of Cincinnati, Cincinnati, Ohio, USA) as previously described [22]. Transgenic mice were generated by breeding mice bearing loxP sites flanking the exon 1 of the Smo gene to mice expressing a Cre recombinase from the Lysozyme M locus (LysMCre), resulting in an predominant recombination in myeloid cells, such as monocytes, macrophages and granulocytes. For these experiments, littermate controls of wild-type $\left(\right.$ Lys-Smo ${ }^{+/+}$), heterozygous $\left(\right.$Lys-Smo ${ }^{+/-}$) or knockout animals (Lys-Smo ${ }^{-1}$ ) were also used. HFD-feeding was performed as described above. Body weight was recorded weekly. Whole body composition (fat mass and lean mass) was determined by using EchoMRI700 (EchoMedical Systems, Houston, USA) on adult chow-fed littermates. Plasma variables were studied as described before [23]. All experiments were approved by the local authorities (Landesdirektion Leipzig).

Study participants Subcutaneous (abdomen) and visceral (omentum majus) fat biopsies were obtained from patients that underwent abdominal surgery for weight reduction, gastric banding, abdominal injuries, cholecystectomy or appendectomy at Leipzig University. Visceral fat area and the relative ratio of intra-abdominal visceral fat to the subcutaneous fat area using computed tomography (CT) scans at the level of L4-L5 was calculated as previously described [24]. In addition, blood and 
serum variables as well as insulin sensitivity were analysed as described in the electronic supplementary material (ESM) Methods section. Patients with severe conditions including generalised inflammation or end stage malignant diseases were excluded from the study. Clinical characteristics of the Leipzig cohort are given in ESM Table 1. The numbers of individuals for specific analyses (indicated in brackets) may deviate from the entire study cohort, because only complete data sets were included. The study was approved by the Ethics Committee of the Leipzig University. All participants gave written informed consent before taking part in the study.

Gene expression analysis in mice and humans Gene expression analysis of mouse and human tissues was performed as described previously [24-26]. Primers for murine genes are listed in ESM Table 2. Human target and housekeeping genes were amplified by specific TaqMan primer and probe assays (DHH, Hs00368306_m1, IHH, Hs00745531_s1; SHH, Hs00179843_m1; HHAT, Hs00911326_m1, HPRT1, Hs01003267_m1; Applied Biosystems, Darmstadt, Germany). HPRT1 was used as housekeeping gene.

ELISA of Hh ligands in serum and tissue Mouse samples were tested for serum and tissue levels of Hh ligands by using an appropriate ELISA kit for either human or mouse $\mathrm{Hh}$ ligands (Human and mouse IHH; both from Cusabio; Wuhan, China; catalogue no. CSB-E $12007 \mathrm{~h}$ and CSB-E16517m; and mouse DHH; EIAab Science; Wuhan, China; catalogue no. E1016m). For determination of Hh tissue levels, protein was extracted by RIPA buffer supplemented with $1 \%$ PMSF and $1 \%$ protease-inhibitor-cocktail (Sigma-Aldrich; Taufkirchen, Germany). Protein content was determined using the BCA protein assay (Pierbo Science; Bonn, Germany). $5 \mu \mathrm{g}$ of protein homogenate or $100 \mu \mathrm{l}$ of sera were applied and measured.

Immunofluorescence and $\mathbf{H} \& \mathbf{E}$ staining Mouse adipose tissue was fixed in formaldehyde and subsequently cryoor paraffin-embedded as described previously [4, 27]. Primary antibodies anti-Patched1, anti-Patched2 (both 1:50; Gene Tex), and anti-SMO (1:50; Abcam; Cambridge, UK), anti-Mac-2 (1:1000; Cedarlane; Burlington, ON, Canada) and anti-PerilipinA (1:200; Abcam), were incubated overnight at $4{ }^{\circ} \mathrm{C}$ followed by fluorochrome-conjugated secondary antibodies (1:200; Invitrogen; Karlsruhe, Germany). Finally, DAPI (1:10,000; Sigma-Aldrich; Deisenhofen, Germany) was used for nuclear counterstaining. Images were taken using an Olympus BX51 epifluorescence microscope (Olympus; Hamburg, Germany). For control stainings, primary antibodies were omitted and sections were stained in parallel as described above. H\&E staining of adipose and liver tissues was performed following standard routines. Adipocyte size and CLS density were quantified as described previously [8]. For detection of SMO on human paraffin sections, the Dako REAL EnVision Detection System (Dako) was used according to the manufacturer's protocol.

Insulin sensitivity and glucose tolerance test Insulin sensitivity tests or glucose tolerance tests on HFD-fed mice were performed as described previously [23]. The investigator was blinded to the genotype.

Live imaging of migration of ATMs in living tissue Staining of ATMs using AlexaFluor647-conjugated isolectin B4 (IB4) from Griffonia simplicifolia (ThermoFisher Scientific; Dreieich, Germany) and subsequent live imaging of adipose tissue explants were performed as described before in detail [28]. Images were obtained every $15 \mathrm{~min}$ and dynamic parameters of ATMs (5 movies per genotype) were validated in an unbiased, automated fashion using the Trackmate plugin from Fiji software 2.0 [29].

Cultivation of adipose tissue explants and drug treatment Epididymal adipose tissue of adult male mice was used to generate organotypic adipose tissue cultures (explants). Briefly, mice were killed, the fat pad was dissected under sterile conditions and further cut into $1 \mathrm{~mm}^{3}$ pieces using a sterile razor blade. Explants were cultured for $24 \mathrm{~h}$ in RPMI medium (Sigma-Aldrich) supplemented with $1 \%$ insulin-transferrin-selenium mixture and antibiotics $(100 \mathrm{U} / \mathrm{ml}$ penicillin and streptomycin; all reagents from Sigma-Aldrich) at $5 \% \mathrm{CO}_{2}, 21 \% \mathrm{O}_{2}$ and $37^{\circ} \mathrm{C}$. Drug treatment was performed for $24 \mathrm{~h}$ with either $1 \mathrm{mmol} / 1$ metformin, $10 \mu \mathrm{mol} / 1$ atorvastatin or $10 \mu \mathrm{mol} / 1$ simvastatin (all Sigma-Aldrich). Activation of simvastatin was performed as previously described [30].

Isolation and cultivation of primary hepatocytes and RNA interference Isolation and cultivation of primary hepatocytes was performed as previously described [26]. Details of this procedure as well as of knockdown of Hhat by RNA interference are given in the ESM Methods section.

Statistical analysis Data are presented as means \pm SEM of at least three animals evaluated by the Student-Newman-Keuls method for multiple comparisons, the Student's $t$ test or Mann-Whitney $U$ test (GraphPad Prism; GraphPad Software, La Jolla, CA, USA). For the RNA interference experiments, a paired Student's $t$ test was used. Linear regression was confirmed using GraphPad software for human data and correlation analyses were performed according to Pearson. All data were checked for statistical 
outliers using the Grubbs' test. A $p$ value $<0.05$ was considered to be statistically significant.

\section{Results}

Hh ligands are increased in mouse obesity To unravel the functional importance of $\mathrm{Hh}$ ligands in obesity, we first studied the expression profile of the three known Hh ligands. In mouse adipose tissue, Dhh and $I h h$ were expressed (Fig. 1a, b), whereas Shh mRNA was not detectable in epididymal or subcutaneous adipose tissue (Fig. 1a, b and ESM Fig. 1). In epididymal adipose tissue, we were unable to detect differential expression of Hh ligands between lean and obese littermates, but in subcutaneous adipose tissue $D h h$ mRNA was increased by twofold in obese mice (Fig. 1b). We performed ELISA analysis from tissue extracts for exact quantification of $\mathrm{Hh}$ tissue abundance in different tissues as well as in the serum. Interestingly, adipose tissue and serum levels of DHH were 15- and 40-fold higher, respectively, compared with $\mathrm{IHH}$. Of note, both circulating $\mathrm{Hh}$ ligands were significantly more abundant in serum and subcutaneous
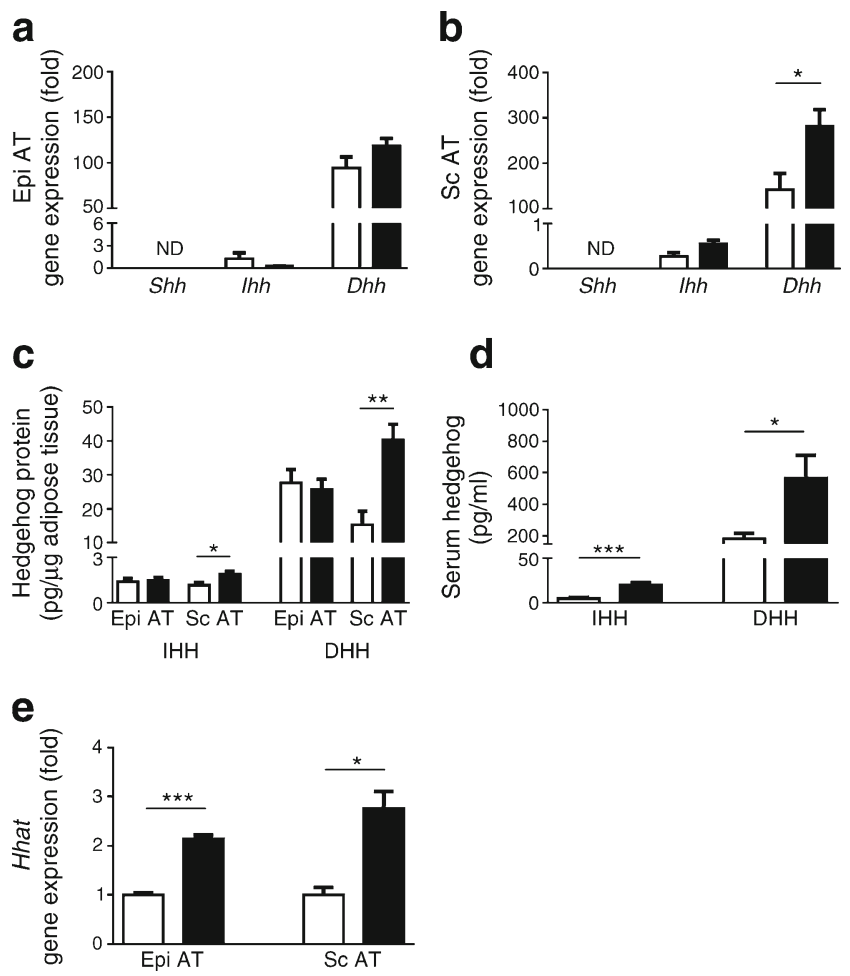

Fig. 1 Hh ligands in mouse adipose tissue from chow-fed (white bars) and HFD-fed (black bars) mice. (a, b) Gene expression data (fold of Ipo8) for $S h h, I h h$ and $D h h$ are presented for epididymal (a; Epi AT; $n=8-9$ ) and subcutaneous adipose tissue (b; Sc AT; $n=4)$ from chow-fed and HFD-fed littermates. (c, d) IHH and DHH abundance in adipose tissue $(n=4)$ as well as in sera $(n=8)$ from chow- and HFD-fed mice tested by ELISA. (e) Gene expression (relative to Ipo8) of Hhat is presented for epididymal and subcutaneous adipose tissue from chow- and HFD-fed littermates. $* p<0.05, * * p<0.01$ and $* * p<0.001$. ND, not detected adipose tissue of obese mice, compared with lean littermates (Fig. 1c, d). We further studied the expression of Hhat, which encodes an enzyme responsible for secretion of Hh ligands $[15,16]$. Indeed, Hhat mRNA was upregulated in epididymal and subcutaneous adipose tissue from obese mice by twofold (Fig. 1e). As proof of principle, we knocked down Hhat by RNA interference in hepatocytes, which mainly express $\mathrm{IHH}$ [31], and verified that $\mathrm{Hh}$ secretion depends on Hhat expression (ESM Fig 2).

Hedgehog receptors are expressed by ATMs We next studied the gene expression of Hh signalling components in
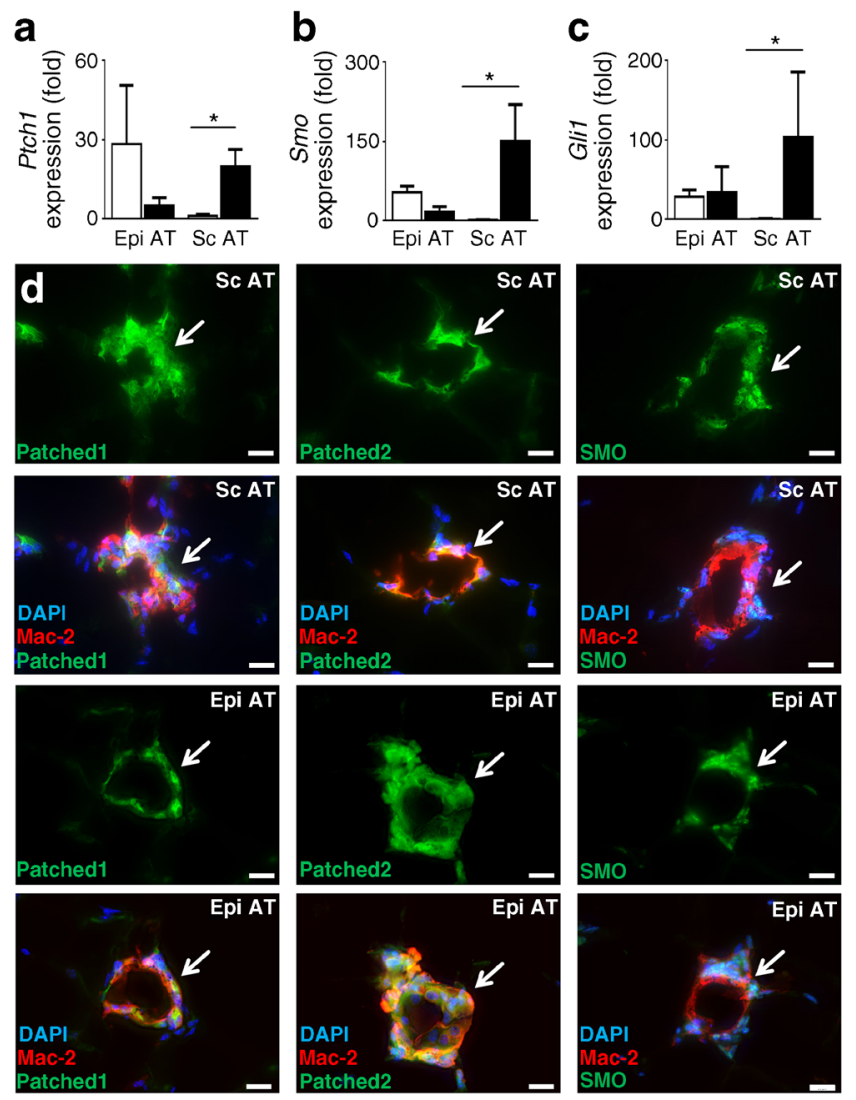

e
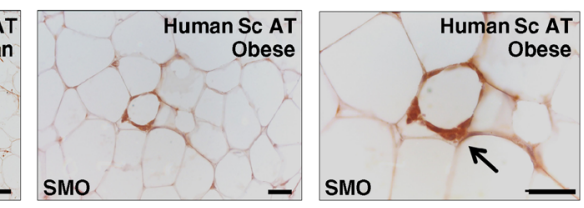

Fig. 2 ATMs express Hh receptors in adipose tissue from obese mice. (a-c) Gene expression data (relative to Actb) for Patched1 (a), Smo (b) and Glil (c) are presented for epididymal (Epi AT) and subcutaneous (Sc AT) adipose tissue from chow-fed (white bars) and HFD-fed (black bars) littermates $(n=4-5)$. (d) Adipose tissue cryo-sections of subcutaneous or epididymal adipose tissue from HFD-fed mice were stained against $\mathrm{Hh}$ receptors Patched1 and Patched2 as well as the Hh co-receptor SMO. Single or triple labelling of the macrophage marker Mac-2 (red), Patched1, Patched 2 or SMO (all in green) and DAPI (blue) are presented. (e) Immunohistochemical detection of SMO in human subcutaneous adipose tissue sections from lean or obese individuals. CLS are marked by arrows. Scale bars are 20 (d) or $50 \mu \mathrm{m}(\mathbf{e}) . * p<0.05$ 
adipose tissue from lean and obese mice. Interestingly, as for $\mathrm{Hh}$ ligands, we found a depot-specific regulation for $\mathrm{Hh}$ signalling components at the mRNA level. In epididymal adipose tissue of obese mice, we found a non-significant downregulation of these components [17, 32]. However, in subcutaneous adipose tissue we found a significant increase of Hh signalling components (Ptch1, Smo and Gli1) in obesity (Fig. 2a-c), as also shown for Hh ligands (Fig. 1b). Using immunofluorescence we could also detect $\mathrm{Hh}$ responsive cells in subcutaneous and epididymal adipose tissue from obese mice. Interestingly, the vast majority of $\mathrm{Hh}$ receptor expression (Patched1, Patched2 and SMO) was found in focal spots of inflammation around dying adipocytes, so-called CLS. Accordingly, co-staining of the macrophage marker Mac-2 confirmed the expression of Hh receptors by ATMs (Fig. 2d; arrows). Further, in human adipose tissue sections from obese individuals, SMO could also be detected in CLS, whereas SMO staining was almost absent in adipose tissue from lean individuals (Fig. 2e). Hence, our data indicate that ATMs are the preferential target of $\mathrm{Hh}$ signalling in adipose tissue from obese mice and humans.

Deficiency of $\mathrm{Hh}$ signalling in myeloid cells impacts on body weight and glucose metabolism Next, we used a conditional knockout model to test the effect of impaired Hh signalling in ATMs in obesity by deletion of the gene encoding the mandatory Hh co-receptor SMO in myeloid cells (Lys-Smo). Lys-Smo mice were generated and characterised in detail by Schumacher et al [22]. Of note, adult Lys-Smo ${ }^{-1-}$ mice were significantly heavier than adult $\mathrm{Lys}_{-} \mathrm{Smo}^{+/+}$. Heterogeneous Lys-Smo ${ }^{+-}$exhibited an intermediate phenotype. Importantly, increased body weight of chow-fed Lys- $\mathrm{Smo}^{-/-}$mice was related to a relative increase of fat mass, rather than lean mass (ESM Fig. 3c, d). In particular, the

Table 1 Characteristics of Lys-Smo ${ }^{-/-}$, Lys-Smo ${ }^{+/}$and Lys-Smo ${ }^{+/+}$mice

\begin{tabular}{lccc}
\hline & Lys-Smo $^{+/+}$ & Lys-Smo $^{+/-}$ & Lys-Smo $^{-/-}$ \\
\hline $\begin{array}{l}\text { Pre-diet body weight (g) } \\
\text { Body weight (g) after }\end{array}$ & $23.7 \pm 2.6$ & $25.8 \pm 2.4$ & $27.6 \pm 2.7^{*}$ \\
$\quad$ 20 weeks of HFD & & $42.8 \pm 5.6$ & $45.8 \pm 5.8^{*}$ \\
$\begin{array}{c}\text { Body weight gain } \\
\quad \% \text { of initial weight) }\end{array}$ & $166.5 \pm 16.0$ & $167.7 \pm 26.9$ & $166.8 \pm 19.9$ \\
$\begin{array}{l}\text { Triacylglycerol (mmol/l) } \\
\text { Cholesterol (mmol/l) }\end{array}$ & $1.10 \pm 0.17$ & $1.01 \pm 0.22$ & $1.17 \pm 0.22$ \\
$\begin{array}{l}\text { HDL-cholesterol } \\
(\mathrm{mmol} / \mathrm{l})\end{array}$ & $4.59 \pm 0.41$ & $3.54 \pm 0.46^{* *}$ & $3.66 \pm 0.55^{* *}$ \\
$\begin{array}{l}\text { LDL-cholesterol } \\
(\mathrm{mmol} / \mathrm{l})\end{array}$ & $0.46 \pm 0.10$ & $0.25 \pm 0.11$ & $0.35 \pm 0.23$ \\
\begin{tabular}{l} 
NEFA (mmol/l) \\
\hline
\end{tabular} & $0.49 \pm 0.08$ & $0.46 \pm 0.11$ & $0.49 \pm 0.08$ \\
\hline
\end{tabular}

Data are presented as means \pm SD and were tested for statistical significance by using one-way ANOVA with a Bonferroni's post hoc multiple comparisons test

$* p<0.05$ or $* * p<0.01$ vs Lys-Smo ${ }^{+/+}$ weight of epididymal adipose tissue was increased in these animals (ESM Fig. 3e, f), suggesting visceral adiposity. However, these alterations did not impact on systemic glucose tolerance or insulin sensitivity in chow-fed animals (ESM Fig. $3 g, h)$. After 20 weeks of HFD all genotypes gained approximately $165 \%$ of initial body weight (Table 1), resulting in a significantly higher body weight of Lys-Smo ${ }^{--}$, compared with Lys-Smo ${ }^{+/+}$(Table 1 and Fig. 3a, b). In line with this, average adipocyte diameter was increased in subcutaneous
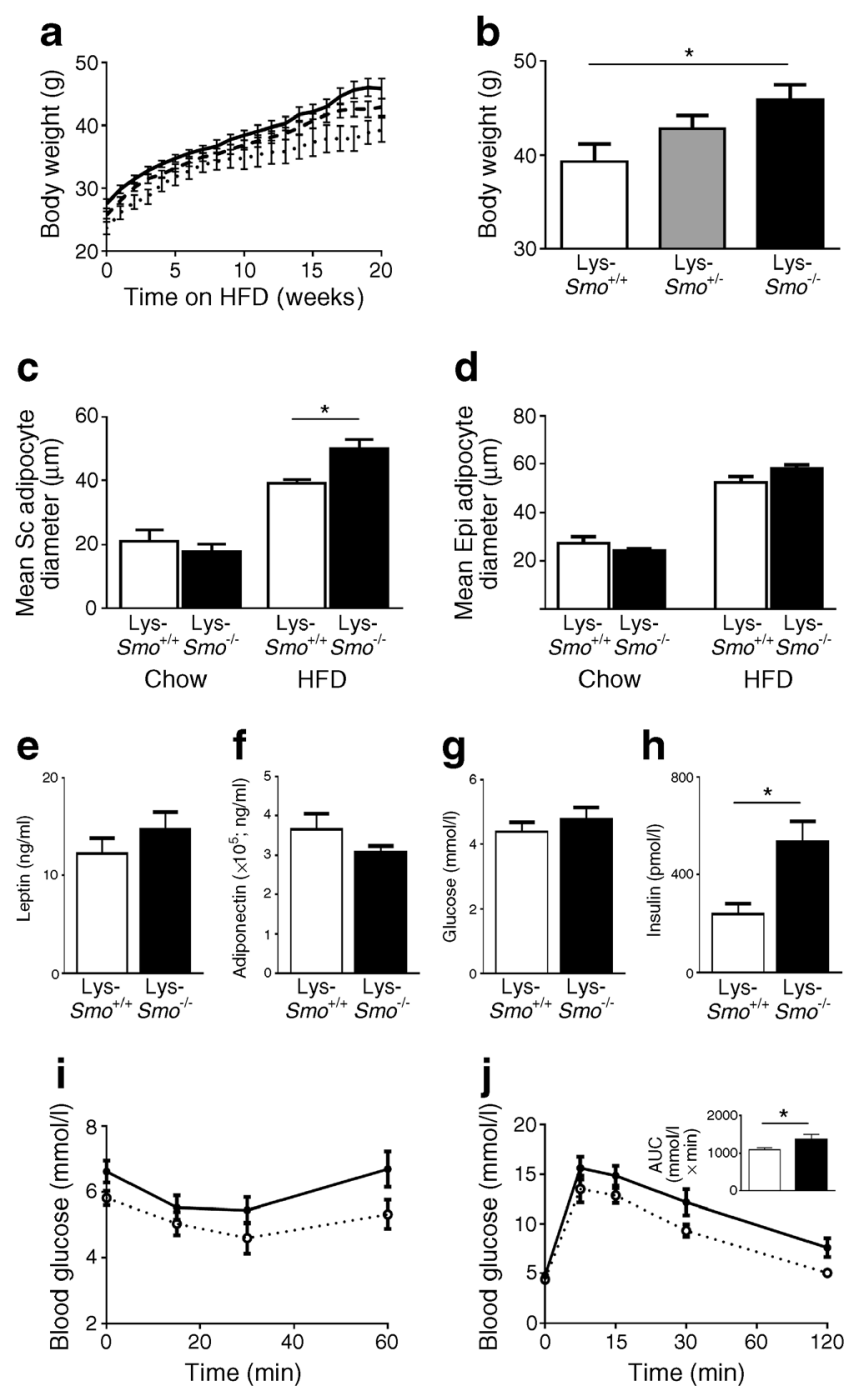

Fig. 3 SMO deficiency in myeloid cells impact on body weight and glucose metabolism. (a) Body weight gain of male Lys-Smo ${ }^{-/}$(solid line), $\mathrm{Lys}_{-} \mathrm{Smo}^{+/-}$(dashed line) and Lys-Smo ${ }^{+/+}$(dotted line) mice ( $n=7-17$ in four independent experiments) for the period of 20 weeks of HFD. (b) Bar graph shows the body weights of each genotype after 20 weeks of HFD. (c, d) Mean adipocyte diameter for adipocytes of subcutaneous ( $\mathrm{Sc} ; \mathbf{c})$ and epididymal (Epi; d) adipose tissue $(n=4-5)$. (e-h) Plasma levels of leptin (e), adiponectin (f), fasting glucose (g) and insulin (h) $(n=5-12)$. (i, j) Blood glucose values of Lys-Smo ${ }^{-/}$(black circles) and Lys-Smo ${ }^{+/+}$(white circles) mice after intraperitoneal insulin $(0.75 \mathrm{U} / \mathrm{kg})(\mathbf{i})$ or glucose injection $(2 \mathrm{~g} / \mathrm{kg})(\mathbf{j})$ over time. Bar graph summarises glucose tolerance test by displaying the AUC of blood glucose levels ( $n=6-10$ in four independent experiments). * $p<0.05$ 
adipose tissue from obese Lys-Smo ${ }^{-1-}$ mice compared with obese Lys-Smo ${ }^{+/+}$mice (Fig. 3c). Importantly, we also found more hypertrophic adipocytes (diameter $>100 \mu \mathrm{m}$ ) in subcutaneous and epididymal adipose tissue from obese Lys-Smo ${ }^{-/}$ mice (ESM Fig. 4a-c). Serum cholesterol was significantly decreased in Lys-Smo ${ }^{-/}$mice compared with Lys-Smo ${ }^{+/}$and Lys-Smo ${ }^{+/+}$mice after HFD as a result of decreased HDLcholesterol. Other serum lipids were unchanged among the groups (Table 1). Further, morphological signs of hepatosteatosis, such as ballooning of hepatocytes, could be identified in HFD-fed Lys-Smo ${ }^{-1-}$, but not in HFD-fed Lys-Smo ${ }^{+/+}$or chow-fed animals (ESM Fig. 4d). In addition, plasma insulin was also significantly increased in HFD-fed Lys-Smo $^{-/}$mice (Fig. 3h). Most importantly, insulin sensitivity and glucose tolerance tests were performed and Lys-Smo ${ }^{-1-}$ animals exhibited impaired glucose tolerance, compared with Lys-Smo ${ }^{+/+}$after HFD (Fig. 3i, j).

Deficiency of $\mathrm{Hh}$ signalling in myeloid cells aggravates adipose tissue inflammation We then studied the impact of SMO deficiency in myeloid cells on adipose tissue inflammation. We found a significant increase of CLS in epididymal adipose tissue of Lys-Smo ${ }^{-/-}$mice after 20 weeks of HFD (Fig. 4a, b). Interestingly, gene expression analysis also revealed changes of inflammatory markers in adipose tissue of obese Lys-Smo ${ }^{-/}$mice. In subcutaneous adipose tissue, $C d 68$ was upregulated as a macrophage marker, whereas in epididymal adipose tissue marker genes of a

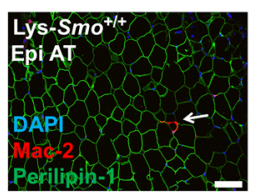

c

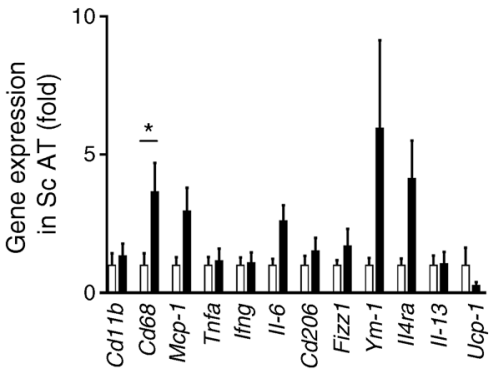

e
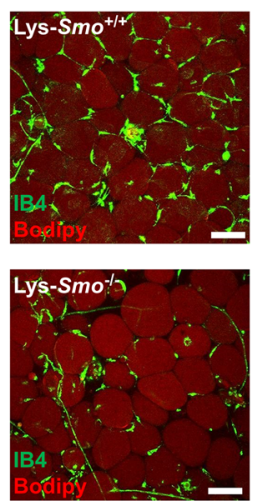

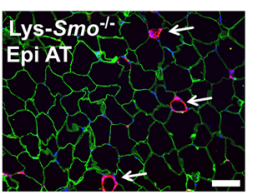

b

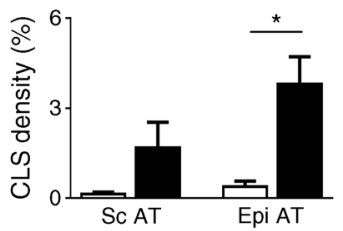

d
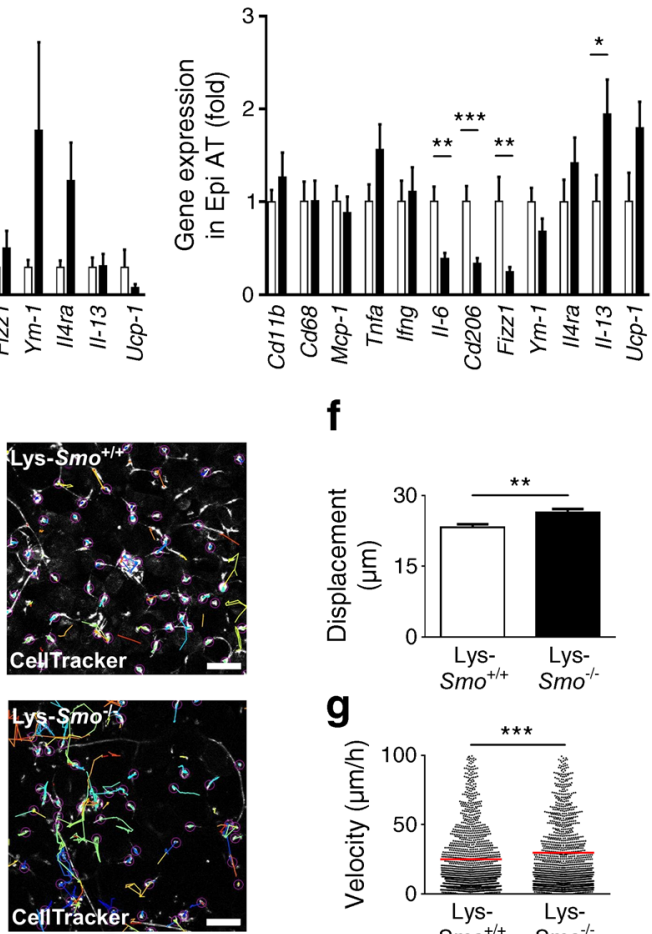

f

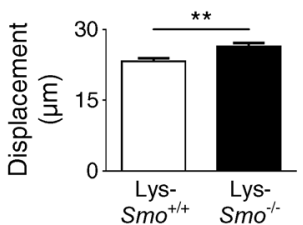

g

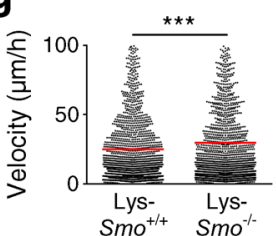

Fig. 4 SMO deficiency in myeloid cells aggravates adipose tissue inflammation in obese mice. (a) Representative images of epididymal adipose tissue from HFD-fed Lys-Smo ${ }^{-/}$and $\mathrm{Lys}_{-} \mathrm{Smo}^{+/+}$mice stained against the adipocyte marker Perilipin-1 (green), the macrophage marker Mac-2 (red) and DAPI (blue), for nuclear counterstain. CLS are indicated by arrows. (b) Bar graph depicts CLS density of HFD-fed Lys-Smo ${ }^{-/}$ (black bars) and Lys-Smo ${ }^{+/+}$(white bars) mice in subcutaneous (Sc AT) and epididymal (Epi AT) adipose tissue. (c, d) Gene expression relative to $36 B 4$ of marker genes of HFD-fed Lys-Smo ${ }^{-1-}$ (black bars) and Lys-Smo $^{+/+}$(white bars) mice in subcutaneous (c) and epididymal (d) adipose tissue $(n=6-11)$. Cd11b, also known as Itgam; Tnfa, also known as Tnf; Cd206, also known as Mrcl; Fizz1, also known as Retnla; Ym-1, also known as Chil3. (e) Images of living adipose tissue explants of $\mathrm{Lys}-S m o^{-1-}$ and Lys-Smo ${ }^{+/+}$. Macrophages and blood vessels are stained using IB4 and adipocytes are stained with Bodipy. Migration analysis is presented for IB4 staining of Lys-Smo ${ }^{-/-}$and Lys-Smo ${ }^{+/+}$over $6 \mathrm{~h}$ (videos are available as ESM). (f, g) Diagrams summarise average macrophage displacement from the starting point (f) and mean migration velocity (g) (5 movies per genotype of four independent experiments). Scale bars are $100 \mu \mathrm{m} .{ }^{*} p<0.05,{ }^{*} p<<0.01$ and $* * * p<0.001$ 
anti-inflammatory M2 polarisation were significantly downregulated (Fig. 4c, d). Further, SMO deficiency in myeloid cells also impacted on dynamic parameters of adipose tissue inflammation as indicated by an elevated migration behaviour of ATMs in obese Lys-Smo ${ }^{-/}$mice, compared with littermate control mice (Fig. 4e-g; ESM Videos 1 and 2).

Hh ligands are altered in human obesity Next, we studied paired visceral and subcutaneous adipose tissue samples from 283 humans. As in mice, $I H H$ and $D H H$ were expressed in visceral and subcutaneous adipose tissue of humans (Fig. 5a, b), whereas $S H H$ was not detectable. In line with this, the expression of SMO could also exclusively be detected by ATMs in human CLS (Fig. 2e) and $D H H$ expression was preferentially found in subcutaneous adipose tissue (Fig. 5d). In contrast to mice, both Hh ligands and HHAT decreased with increasing BMI, but only the decline of $\mathrm{DHH}$ and HHAT mRNA reached statistical significance (Fig. $5 \mathrm{a}-\mathrm{c})$. Furthermore, in our cohort highly significant negative correlations of $D H H$ and HHAT with other obesity variables, such as body weight, waist and hip circumferences, percentage of body fat and fat area were found (Tables 2 and 4). In contrast, $I H H$ expression did not correlate with the vast majority of obesity variables (Table 3 ). According to the reduction of HHAT mRNA in human obesity, analysis of human serum samples also revealed a significant reduction of circulating $\mathrm{Hh}$ ligands in morbidly obese compared with lean and overweight individuals (Fig. 5e). Interestingly, morbidly obese individuals $\left(\mathrm{BMI}>40 \mathrm{~kg} / \mathrm{m}^{2}\right.$ ) with normal glucose metabolism $\left(\mathrm{HbA}_{1 \mathrm{c}}<6 \%\right)$ exhibited significantly higher serum levels of $\mathrm{IHH}$, compared with patients with type 2 diabetes $\left(\mathrm{HbA}_{1 \mathrm{c}}>7 \%\right.$; Fig. 5f). In line with this, indicators for insulin resistance within our cohort (glucose infusion rate during euglycaemic-hyperinsulinaemic clamp tests, $\mathrm{HbA}_{1 \mathrm{c}}$, fasting plasma insulin [FPI] and blood glucose after glucose challenge) correlated negatively with HHAT expression, whereas indicators of a metabolically healthy obese phenotype, such as HDL-cholesterol and adiponectin, correlated positively with HHAT mRNA (Table 4).

We further hypothesised that the unexpected decrease of Hh ligands in human obesity and type 2 diabetes could be related to environmental factors, such as drug intake. Therefore, we studied the impact of atorvastatin, simvastatin and metformin on Dhh, Ihh and Hhat mRNA expression in murine adipose tissue explants; statins and metformin represent first line treatment of hypercholesterolemia or type 2 diabetes, respectively [33]. Most interestingly, metformin decreased $D h h$ and $I h h$ expression, without affecting Hhat or Casp3 (encoding caspase 3) expression (data not shown), therefore excluding a cell-toxic effect (Fig. 5g-i).
Fig. 5 Hh ligands and HHAT expression in human obesity. (a-c) Gene expression (fold of $H P R T 1)$ of $D H H(\mathbf{a})(n=301)$, $I H H(\mathbf{b})(n=630)$ and HHAT (c) $(n=218)$ in human subcutaneous (Sc) adipose tissue. (d) Expression of $D H H$ in paired visceral (Vis) and subcutaneous adipose tissue $(n=77-79)$. (e) Serum IHH of lean and overweight (BMI $<30 \mathrm{~kg} / \mathrm{m}^{2}$; $n=18$ ) and morbidly obese humans (BMI $>40 \mathrm{~kg} / \mathrm{m}^{2} ; n=35$ ). (f) Serum IHH level for metabolically healthy obese (BMI $>40 \mathrm{~kg} / \mathrm{m}^{2} ; \mathrm{HbA}_{1 \mathrm{c}} 5-6 \%$ or $31.1-42.1 \mathrm{mmol} / \mathrm{mol} ; n=18$ ) and obese patients suffering from type 2 diabetes (BMI $>40 \mathrm{~kg} / \mathrm{m}^{2}$; $\mathrm{HbA}_{1 \mathrm{c}}>7 \%$ or $>53 \mathrm{mmol} / \mathrm{mol}$; $n=5)$. $(\mathbf{g}-\mathbf{i})$ Expression analyses for $\operatorname{Dhh}(\mathbf{g}), \operatorname{Ihh}(\mathbf{h})$ and Hhat (i) relative to $I p o 8$ in murine adipose tissue explants after $24 \mathrm{~h}$ of stimulation with atorvastatin (10 $\mu \mathrm{mol} / \mathrm{l})$, simvastatin $(10 \mu \mathrm{mol} / \mathrm{l})$ or metformin ( $1 \mathrm{mmol} / \mathrm{l}) . * p<0.05, * * p<0.01$ and $* * * p<0.001$
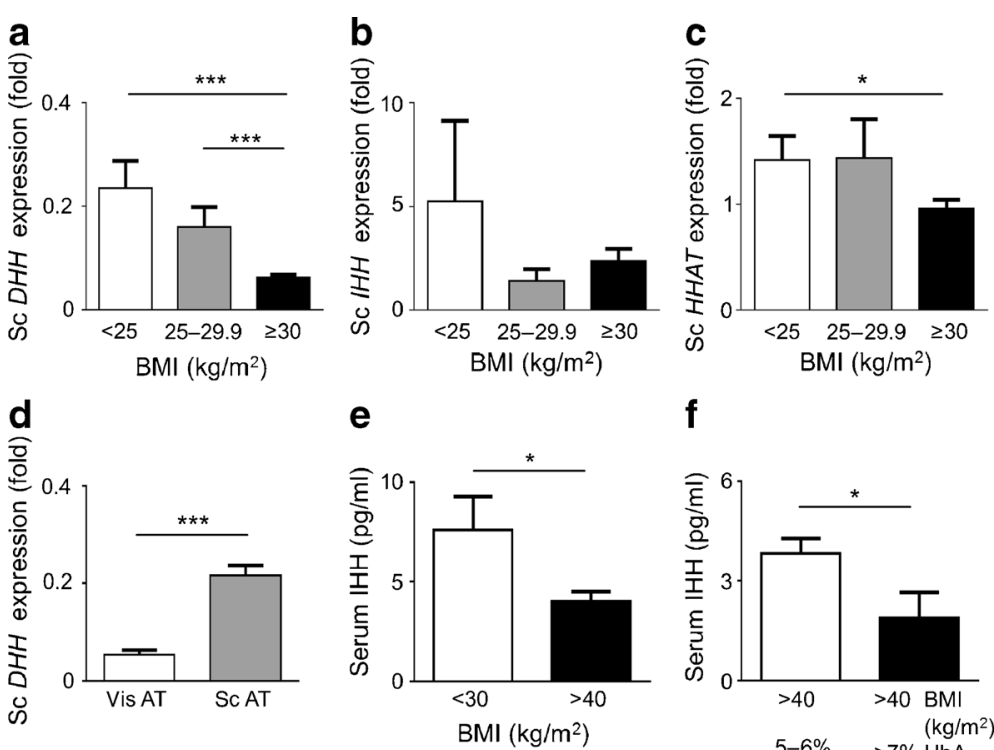

f
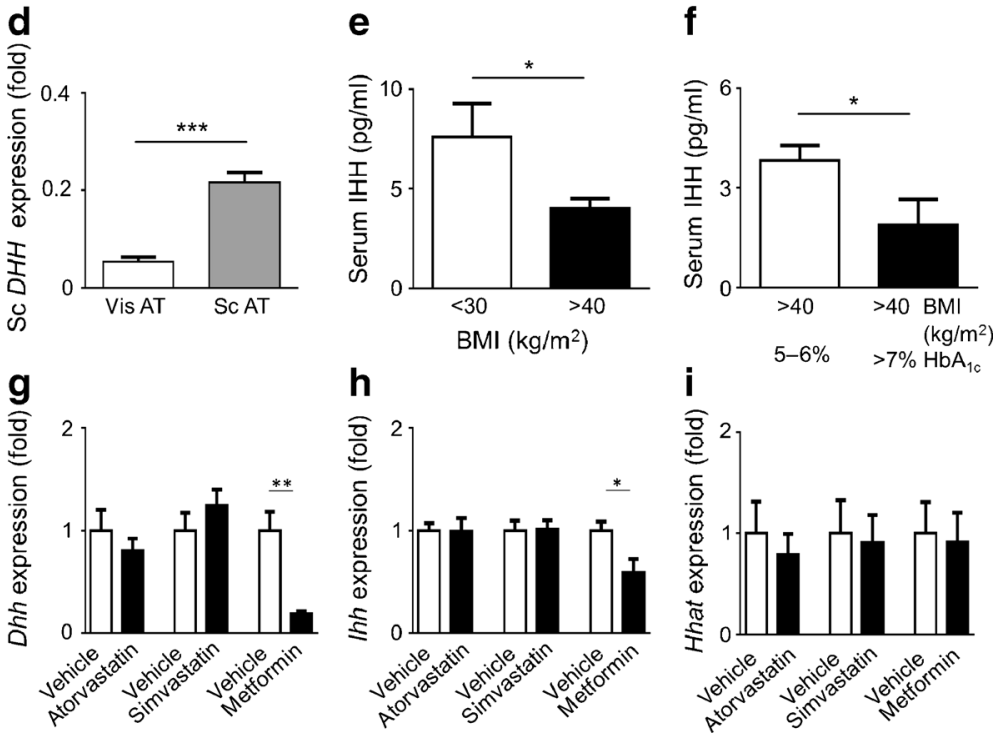
Table 2 Correlation analysis of visceral and subcutaneous adipose tissue $D H H$ mRNA levels of the entire study group $(N=289)$

\begin{tabular}{|c|c|c|}
\hline & $\begin{array}{l}\text { Vis } D H H \\
(r ; p)\end{array}$ & $\begin{array}{l}\text { Sc } D H H \\
(r ; p)\end{array}$ \\
\hline Age (years) & $0.020 ; 0.833$ & $0.193 ; 0.041^{*}$ \\
\hline CT ratio & $0.354 ; 0.163$ & $0.661 ; 0.002^{* *}$ \\
\hline Weight (kg) & $0.041 ; 0.674$ & $-0.385 ;<0.0001^{* * * *}$ \\
\hline BMI $\left(\mathrm{kg} / \mathrm{m}^{2}\right)$ & $-0.004 ; 0.969$ & $-0.392 ;<0.0001^{* * * *}$ \\
\hline WHR & $-0.373 ; 0.105$ & $-0.341 ; 0.120$ \\
\hline Waist (cm) & $-0.262 ; 0.117$ & $-0.423 ; 0.007^{* *}$ \\
\hline Hip (cm) & $-0.148 ; 0.522$ & $-0.250 ; 0.251$ \\
\hline Body fat (\%) & $-0.596 ; 0.090$ & $-0.725 ; 0.027^{*}$ \\
\hline Sc fat area $\left(\mathrm{cm}^{2}\right)$ & $-0.519 ; 0.033^{*}$ & $-0.535 ; 0.018^{*}$ \\
\hline Vis fat area $\left(\mathrm{cm}^{2}\right)$ & $-0.476 ; 0.053$ & $-0.250 ; 0.303$ \\
\hline $\mathrm{HbA}_{1 \mathrm{c}}(\%$ or $\mathrm{mmol} / \mathrm{mol})$ & $0.122 ; 0.380$ & $0.038 ; 0.785$ \\
\hline FPG $(\mathrm{mmol} / \mathrm{l})$ & $0.017 ; 0.863$ & $-0.110 ; 0.258$ \\
\hline FPI (pmol/l) & $-0.458 ; 0.028^{*}$ & $-0.423 ; 0.040^{*}$ \\
\hline $2 \mathrm{~h}$ OGTT $(\mathrm{mmol} / \mathrm{l})$ & $-0.150 ; 0.700$ & $-0.137 ; 0.707$ \\
\hline $\operatorname{GIR}\left(\mathrm{mg} \mathrm{kg}^{-1} \min ^{-1}\right)$ & $0.628 ; 0.012^{*}$ & $0.293 ; 0.271$ \\
\hline Cholesterol (mmol/l) & $-0.002 ; 0.984$ & $-0.181 ; 0.099$ \\
\hline HDL-cholesterol (mmol/l) & $0.074 ; 0.590$ & $0.173 ; 0.195$ \\
\hline LDL-cholesterol (mmol/l) & $0.012 ; 0.930$ & $-0.256 ; 0.048^{*}$ \\
\hline Triacylglycerol (mmol/1) & $0.072 ; 0.513$ & $-0.202 ; 0.060$ \\
\hline NEFA (mmol/1) & $-0.831 ;<0.0001^{* * *}$ & $-0.377 ; 0.063$ \\
\hline Leptin (pg/ml) & $-0.726 ; 0.001^{* *}$ & $-0.557 ; 0.016^{*}$ \\
\hline Adiponectin $(\mu \mathrm{g} / \mathrm{ml})$ & $0.499 ; 0.049^{*}$ & $0.340 ; 0.167$ \\
\hline CRP (nmol/1) & $0.051 ; 0.609$ & $-0.251 ; 0.009^{* *}$ \\
\hline IL-6 (pg/ml) & $-0.352 ; 0.182$ & $-0.413 ; 0.089$ \\
\hline FT3 (pmol/l) & $0.132 ; 0.409$ & $-0.045 ; 0.772$ \\
\hline Creatinine $(\mu \mathrm{mol} / \mathrm{l})$ & $0.143 ; 0.151$ & $-0.243 ; 0.012^{*}$ \\
\hline $\operatorname{ALT}(\mu \mathrm{kat} / \mathrm{l})$ & $-0.154 ; 0.111$ & $-0.211 ; 0.026^{*}$ \\
\hline AST $(\mu \mathrm{kat} / \mathrm{l})$ & $0.016 ; 0.880$ & $-0.189 ; 0.068$ \\
\hline GGT $(\mu \mathrm{kat} / \mathrm{l})$ & $-0.094 ; 0.343$ & $-0.246 ; 0.011^{*}$ \\
\hline
\end{tabular}

All data were $\log$ transformed $\left(\log _{10}\right)$ and data are shown as correlation coefficient $(r)$ and $p$ value $(p)$. ${ }^{*} p<0.05,{ }^{* *} p<0.01, * * * p<0.001$

Intercorrelation between Vis $D H H$ and Sc $D H H$ mRNA: $r=0.094$; $p=0.110$

After adjustment for BMI, age and sex all correlations are gone

ALT, alanine aminotransferase; AST, aspartate aminotransferase; CRP, C-reactive protein; FPG, free plasma glucose; FPI, free plasma insulin; FT3, free triiodothyronine; GGT, $\gamma$-glutamyltransferase; GIR, glucose infusion rate; Sc, subcutaneous; Vis, visceral

\section{Discussion}

Hh has recently been suggested as a potential drug target owing to its potential to lower blood glucose and inhibit adipose tissue development $[18,20]$. These studies were performed using genetic mouse models or pharmacological approaches to inhibit or stimulate Hh signalling in adipose tissue, respectively. However, the physiological regulation of Hh ligands in obesity and type 2 diabetes is ill defined. We
Table 3 Correlation analysis of visceral and subcutaneous adipose tissue $I H H$ mRNA levels $(N=283)$

\begin{tabular}{|c|c|c|}
\hline & $\begin{array}{l}\text { Vis } I H H \\
(r ; p)\end{array}$ & $\begin{array}{l}\mathrm{Sc} I H H \\
(r ; p)\end{array}$ \\
\hline Age (years) & $0.036 ; 0.485$ & $0.052 ; 0.290$ \\
\hline CT ratio & $0.039 ; 0.699$ & $-0.010 ; 0.920$ \\
\hline Weight (kg) & $-0.039 ; 0.452$ & $0.002 ; 0.972$ \\
\hline BMI $\left(\mathrm{kg} / \mathrm{m}^{2}\right)$ & $-0.035 ; 0.469$ & $0.010 ; 0.846$ \\
\hline WHR & $0.164 ; 0.088$ & $0.158 ; 0.092$ \\
\hline Waist (cm) & $-0.022 ; 0.790$ & $0.019 ; 0.804$ \\
\hline Hip (cm) & $-0.144 ; 0.940$ & $-0.007 ; 0.940$ \\
\hline Body fat (\%) & $-0.216 ; 0.047^{*}$ & $-0.085 ; 0.158$ \\
\hline Sc fat area $\left(\mathrm{cm}^{2}\right)$ & $0.038 ; 0.708$ & $0.150 ; 0.129$ \\
\hline Vis fat area $\left(\mathrm{cm}^{2}\right)$ & $0.092 ; 0.369$ & $0.210 ; 0.033^{*}$ \\
\hline $\mathrm{HbA}_{1 \mathrm{c}}(\%$ or $\mathrm{mmol} / \mathrm{mol})$ & $0.029 ; 0.676$ & $-0.035 ; 0.598$ \\
\hline FPG (mmol/l) & $-0.033 ; 0.530$ & $-0.034 ; 0.498$ \\
\hline FPI (pmol/l) & $-0.035 ; 0.697$ & $-0.014 ; 0.875$ \\
\hline 2 h OGTT $(\mathrm{mmol} / \mathrm{l})$ & $0.022 ; 0.868$ & $0.086 ; 0.491$ \\
\hline GIR (mg kg $\left.{ }^{-1} \min ^{-1}\right)$ & $-0.285 ; 0.032^{*}$ & $-0.135 ; 0.344$ \\
\hline Cholesterol (mmol/l) & $-0.005 ; 0.939$ & $-0.018 ; 0.776$ \\
\hline HDL-cholesterol (mmol/l) & $-0.023 ; 0.760$ & $-0.007 ; 0.920$ \\
\hline LDL-cholesterol (mmol/l) & $0.051 ; 0.509$ & $0.037 ; 0.620$ \\
\hline Triacylglycerol (mmol/l) & $-0.007 ; 0.912$ & $-0.035 ; 0.560$ \\
\hline NEFA (mmol/l) & $-0.127 ; 0.219$ & $-0.009 ; 0.931$ \\
\hline Leptin (pg/ml) & $-0.151 ; 0124$ & $0.020 ; 0.838$ \\
\hline Adiponectin $(\mu \mathrm{g} / \mathrm{ml})$ & $-0.018 ; 0.858$ & $0.014 ; 0.887$ \\
\hline $\mathrm{CRP}(\mathrm{nmol} / \mathrm{l})$ & $0.076 ; 0.148$ & $0.122 ; 0.015^{*}$ \\
\hline IL-6 (pg/ml) & $-0.239 ; 0.035^{*}$ & $0.025 ; 0.826$ \\
\hline FT3 (pmol/l) & $0.152 ; 0.102$ & $-0.048 ; 0.601$ \\
\hline Creatinine $(\mu \mathrm{mol} / \mathrm{l})$ & $0.082 ; 0.118$ & $0.198 ; 0.0001^{* * * *}$ \\
\hline $\operatorname{ALT}(\mu \mathrm{kat} / \mathrm{l})$ & $-0.088 ; 0.097$ & $-0.109 ; 0.031$ \\
\hline AST $(\mu \mathrm{kat} / \mathrm{l})$ & $-0.048 ; 0.386$ & $-0.027 ; 0.601$ \\
\hline GGT ( $\mu$ kat/l) & $-0.046 ; 0.389$ & $-0.039 ; 0.448$ \\
\hline
\end{tabular}

All data were $\log$ transformed $\left(\log _{10}\right)$ and data are shown as correlation coefficient $(r)$ and $p$ value $(p) . * p<0.05, * * * p<0.001$

Intercorrelation between Vis $I H H$ and Sc $I H H$ mRNA: $r=0.433$; $p<0.001$

After adjustment for BMI, age and sex all correlations are gone

ALT, alanine aminotransferase; AST, aspartate aminotransferase; CRP, C-reactive protein; FPG, free plasma glucose; FPI, free plasma insulin; FT3, free triiodothyronine; GGT, $\gamma$-glutamyltransferase; GIR, glucose infusion rate; Sc, subcutaneous; Vis, visceral

here report that DHH and IHH are the preferential local $\mathrm{Hh}$ ligands in adipose tissue. Further, subcutaneous adipose tissue is more prone to obesity-associated regulation of the $\mathrm{Hh}$ pathway than visceral adipose tissue. In addition, extracellular Hh abundance depends on Hhat expression, rather than on Dhh or Ihh gene expression, as shown by Hhat knockdown in hepatocytes. HHAT is an enzyme involved in secretion of Hh ligands $[15,16]$, and this enzyme is also upregulated in epididymal adipose tissue from obese mice. In line with this, 
Table 4 Correlation analysis of visceral and subcutaneous adipose tissue HHAT mRNA levels $(N=283)$

\begin{tabular}{|c|c|c|}
\hline & $\begin{array}{l}\text { Vis } H H A T \\
(r ; p)\end{array}$ & $\begin{array}{l}\mathrm{Sc} H H A T \\
(r ; p)\end{array}$ \\
\hline Age (years) & $0.110 ; 0.108$ & $0.166 ; 0.014^{*}$ \\
\hline CT ratio & $0.109 ; 0.140$ & $0.141 ; 0.056$ \\
\hline Weight $(\mathrm{kg})$ & $-0.053 ; 0.440$ & $-0.253 ;<0.001^{* * * *}$ \\
\hline BMI $\left(\mathrm{kg} / \mathrm{cm}^{2}\right)$ & $-0.077 ; 0.256$ & $-0.278 ;<0.001^{* * * *}$ \\
\hline WHR & $0.038 ; 0.576$ & $-0.083 ; 0.222$ \\
\hline Waist (cm) & $-0.047 ; 0.492$ & $-0.254 ;<0.001^{* * * *}$ \\
\hline Hip (cm) & $-0.073 ; 0.283$ & $-0.254 ;<0.001^{* * * *}$ \\
\hline Body fat (\%) & $-0.054 ; 0.522$ & $-0.364 ;<0.001^{* * * *}$ \\
\hline Sc fat area $\left(\mathrm{cm}^{2}\right)$ & $-0.310 ;<0.001^{* * * *}$ & $-0.167 ; 0.024^{*}$ \\
\hline Vis fat area $\left(\mathrm{cm}^{2}\right)$ & $-0.341 ;<0.001^{* * * *}$ & $-0.167 ; 0.023^{*}$ \\
\hline $\mathrm{HbA}_{1 \mathrm{c}}(\%$ or $\mathrm{mmol} / \mathrm{mol})$ & $-0.007 ; 0.919$ & $-0.213 ; 0.002^{* * *}$ \\
\hline $\mathrm{FPG}(\mathrm{mmol} / \mathrm{l})$ & $0.016 ; 0.816$ & $-0.052 ; 0.446$ \\
\hline FPI (pmol/l) & $-0.065 ; 0.403$ & $-0.159 ; 0.041^{*}$ \\
\hline 2 h OGTT $(\mathrm{mmol} / \mathrm{l})$ & $-0.146 ; 0.175$ & $-0.222 ; 0.041^{*}$ \\
\hline $\operatorname{GIR}\left(\mathrm{mg} \mathrm{kg}^{-1} \min ^{-1}\right)$ & $0.208 ; 0.045^{*}$ & $0.291 ; 0.005^{* *}$ \\
\hline Cholesterol (mmol/l) & $0.034 ; 0.707$ & $0.087 ; 0.326$ \\
\hline HDL-cholesterol (mmol/l) & $0.103 ; 0.259$ & $0.256 ; 0.004^{* *}$ \\
\hline LDL-cholesterol (mmol/l) & $-0.032 ; 0.740$ & $0.009 ; 0.922$ \\
\hline Triacylglycerol (mmol/l) & $0.017 ; 0.842$ & $-0.080 ; 0.357$ \\
\hline NEFA (mmol/l) & $-0.064 ; 0.434$ & $-0.149 ; 0.067$ \\
\hline Leptin (pg/ml) & $-0.062 ; 0.444$ & $-0.308 ;<0.001^{* * *}$ \\
\hline Adiponectin $(\mu \mathrm{g} / \mathrm{ml})$ & $0.169 ; 0.033^{*}$ & $0.231 ; 0.003^{* * *}$ \\
\hline $\mathrm{CRP}(\mathrm{nmol} / \mathrm{l})$ & $0.160 ; 0.025^{*}$ & $0.085 ; 0.235$ \\
\hline IL-6 (pg/ml) & $-0.048 ; 0.550$ & $-0.177 ; 0.142$ \\
\hline FT3 (pmol/1) & $-0.252 ; 0.019^{*}$ & $-0.149 ; 0.174$ \\
\hline Creatinine $(\mu \mathrm{mol} / \mathrm{l})$ & $0.148 ; 0.037^{*}$ & $0.148 ; 0.036^{*}$ \\
\hline $\operatorname{ALT}(\mu \mathrm{kat} / \mathrm{l})$ & $0.074 ; 0.339$ & $-0.101 ; 0.186$ \\
\hline AST $(\mu \mathrm{kat} / \mathrm{l})$ & $0.181 ; 0.018^{*}$ & $0.072 ; 0.349$ \\
\hline GGT $(\mu \mathrm{kat} / \mathrm{l})$ & $0.027 ; 0.741$ & $0.105 ; 0.185$ \\
\hline
\end{tabular}

All data were $\log$ transformed $\left(\log _{10}\right)$ and data are shown as correlation coefficient $(r)$ and $p$ value $(p)$. ${ }^{*} p<0.05, * * p<0.01, * * * p<0.001$

Intercorrelation between Vis HHAT and Sc HHAT mRNA: $r=0.467$; $p<0.0001$

After adjustment for BMI, age and sex all correlations are gone

ALT, alanine aminotransferase; AST, aspartate aminotransferase; CRP, C-reactive protein; FPG, free plasma glucose; FPI, free plasma insulin; FT3, free triiodothyronine; GGT, $\gamma$-glutamyltransferase; GIR, glucose infusion rate; Sc, subcutaneous; Vis, visceral

IHH serum abundance also increased in obesity, without detectable regulation on mRNA level in either depot.

Next, we studied the expression of $\mathrm{Hh}$ receptors in adipose tissue by immunofluorescence to identify potential target cells of Hh signalling. Although visceral adipocytes and macrophages downregulate $\mathrm{Hh}$ signalling components in obesity [32], ATMs were the only cell type with detectable Hh receptor expression in adipose tissue from obese mice and, therefore, represent $\mathrm{Hh}$ target cells in adipose tissue from obese mice. Similarly, Todoric et al have previously reported preferential expression of Hh signalling components by macrophages in adipose tissue [32].

Therefore, we used a conditional knockout model of SMO deficiency in myeloid cells using LysMCre driven recombination (Lys-Smo ${ }^{--}$) to study the impact of $\mathrm{Hh}$ signalling on obesity-associated adipose tissue inflammation. Importantly, ectopic activity of the Cre recombinase in approximately $10 \%$ of brain neurons was described in this model [34]. However, unaffected food intake in Lys-Smo ${ }^{-/}$ mice and macrophage-specific alterations ex vivo suggest a predominate effect of SMO deficiency in myeloid cells.

Of note, Lys-Smo ${ }^{-/-}$mice exhibited a higher body weight compared with control. Detailed analysis could confirm preferential visceral fat accumulation in chow-fed Lys-Smo ${ }^{-/}$ mice, without affecting systemic glucose metabolism. After feeding these mice an HFD, the higher body weight of Lys$\mathrm{Smo}^{-/-}$mice was even more pronounced. Importantly, macrophages are crucial for adipocyte differentiation and adipose tissue development in vivo [35-37], a mechanism that might explain our findings. Further, obese Lys-Smo ${ }^{-/}$mice suffered from an aggravated metabolic dysfunction, as shown by impaired glucose tolerance and decreased HDL-cholesterol. This metabolic dysfunction is most likely to be due to aggravated adipose tissue inflammation, characterised by an increase in CLS and an enhanced migratory velocity. Of note, an increase in ATM migration correlates with adipose tissue inflammation [38]. However, in contrast to other anti-inflammatory markers, $I l-13$ was elevated in epididymal adipose tissue; $I l-13$ is usually increased in adipose tissue from obese mice $[39,40]$ and might be responsible for obesity-associated ATM proliferation (unpublished data).

Next, we aimed at extending our knowledge on expression and regulation of Hh ligands in obesity to human tissue. First, we found that in human adipose tissue $D H H$ and $I H H$ were also expressed, whereas we were unable to detect $S H H$. Notably, in sharp contrast to mice, DHH, IHH and HHAT were downregulated with increasing BMI. This was also verified at the protein level for circulating IHH. IHH was significantly decreased in serum from obese and diabetic participants, potentially due to a decrease in HHAT expression in human obesity. Importantly, HHAT upregulation is the best correlate of metabolic recovery after bariatric surgery in humans [41].

However, the reason for the contrary regulation of $\mathrm{Hh}$ ligands in mouse and human obesity is unknown. In general, the physiological regulation of Hh ligands is poorly understood. Notably, cholesterol represents an essential component of post-translational modification of $\mathrm{Hh}$ [42] and pharmacological inhibition of cholesterol biosynthesis decreases Hh expression [43]. Further, the glucose-lowering drug metformin also impacts on Hh expression [44, 45]. In our study, statin treatment did not alter Hh expression, but metformin significantly reduces $D h h$ and $I h h$ expression in 
adipose tissue explants. Since the vast majority of our diabetes patients regularly take metformin, metformin could counteract a diabetes-induced upregulation of $\mathrm{Hh}$ ligands. In addition, intrinsic differential relationships between the expression of specific genes in adipose tissue from mice or humans were reported in systematic comparisons of developmental genes [46]. Therefore, we cannot exclude intrinsic differences between humans and mice in the regulation of Hh expression. To address this hypothesis, further human studies including pharmacotherapy-naive individuals are required.

We here show that inhibition of Hh signalling in myeloid cells increases body weight, aggravates adipose tissue inflammation and impairs glucose metabolism in mice. Therefore, a decrease in local and circulating Hh ligands within adipose tissue from obese patients could contribute to metabolic dysfunction and may represent a novel target to treat adipose tissue dysfunction and type 2 diabetes.

Acknowledgements We are grateful for the excellent technical assistance of A. Ehrlich and C. Merkwitz (Institute of Anatomy, Leipzig University). We also thank A. Pospisilik (Max Planck Institute of Immunobiology and Epigenetics, Freiburg, Germany) and H. Esterbauer (Department of Laboratory Medicine, Medical University of Vienna, Vienna, Austria) for helpful discussions and K. Jäger and A. Lösche from the FACS core unit (Leipzig University).

Data availability The data that support the findings of this study are available from the corresponding author upon reasonable request.

Funding This work was further supported by the Kompetenznetz Adipositas (Competence Network for Obesity) funded by the Federal ministry of Education and Research (German Obesity Biomaterial Bank; FKZ 01GI1128; FKZ 01EO1001; IFB FKZ 01E011501 and Virtual Liver Network: FKZ 0315735), a grant from the Deutsche Forschungsgemeinschaft DFG-SFB 1052/1: 'Obesity mechanisms' (projects A04, B01, B04, B09), the German Center of Diabetes Research (DZD 82DZD00601) and by the Helmholtz alliance 'Imaging and Curing Environmental Metabolic Disease'.

Duality of interest The authors declare that there is no duality of interest associated with this manuscript.

Contribution statement JB, SK and MM-S designed, performed and analysed protein and gene expression of murine tissues. $\mathrm{CH}, \mathrm{IB}, \mathrm{MG}$ and UW designed, performed and analysed morphological characterisation of murine adipose tissue samples. JB, MM-S and RG planned, performed and analysed cell culture experiments. YZ, AK and NK planned, performed and analysed metabolic characterisation of knockout mice. $\mathrm{MK}$ and $\mathrm{MB}$ planned, performed and analysed data from human cohorts. IB and MG designed, performed and evaluated live imaging experiments of adipose tissue explants. JB, UW and MG designed the study. JB and MG wrote the paper. All authors participated in drafting and revising this article. All authors approved the final version of the manuscript. MG takes full responsibility for the content of this article and is the guarantor of this work.

\section{References}

1. James WP (2008) WHO recognition of the global obesity epidemic. Int J Obes 32(Suppl 7):S120-S126

2. Weisberg SP, McCann D, Desai M, Rosenbaum M, Leibel RL, Ferrante AW (2003) Obesity is associated with macrophage accumulation in adipose tissue. J Clin Invest 112:1796-1808

3. Cinti S (2005) Adipocyte death defines macrophage localization and function in adipose tissue of obese mice and humans. J Lipid Res 46:2347-2355

4. Haase J, Weyer U, Immig K et al (2014) Local proliferation of macrophages in adipose tissue during obesity-induced inflammation. Diabetologia 57:562-571

5. Lumeng CN, Deyoung SM, Bodzin JL, Saltiel AR (2007) Increased inflammatory properties of adipose tissue macrophages recruited during diet-induced obesity. Diabetes 56:16-23

6. Hotamisligil GS, Shargill NS, Spiegelman BM (1993) Adipose expression of tumor necrosis factor-alpha: direct role in obesitylinked insulin resistance. Science 259:87-91

7. Klöting N, Fasshauer M, Dietrich A et al (2010) Insulin-sensitive obesity. Am J Physiol Endocrinol Metab 299:E506-E515

8. du Plessis J, van Pelt J, Korf H et al (2015) Association of adipose tissue inflammation with histologic severity of nonalcoholic fatty liver disease. Gastroenterology 149(635-648):e614

9. Nusslein-Volhard C, Wieschaus E (1980) Mutations affecting segment number and polarity in Drosophila. Nature 287:795-801

10. Ingham PW, McMahon AP (2001) Hedgehog signaling in animal development: paradigms and principles. Genes Dev 15:3059-3087

11. Varjosalo M, Taipale J (2008) Hedgehog: functions and mechanisms. Genes Dev 22:2454-2472

12. Taipale J, Beachy PA (2001) The Hedgehog and Wnt signalling pathways in cancer. Nature 411:349-354

13. McMahon AP, Ingham PW, Tabin CJ (2003) Developmental roles and clinical significance of hedgehog signaling. Curr Top Dev Biol 53:1-114

14. Pan J, Wang Q, Snell WJ (2005) Cilium-generated signaling and cilia-related disorders. Lab Investig 85:452-463

15. Chamoun Z, Mann RK, Nellen D et al (2001) Skinny hedgehog, an acyltransferase required for palmitoylation and activity of the hedgehog signal. Science 293:2080-2084

16. Chen MH, Li YJ, Kawakami T, Xu SM, Chuang PT (2004) Palmitoylation is required for the production of a soluble multimeric Hedgehog protein complex and long-range signaling in vertebrates. Genes Dev 18:641-659

17. Suh JM, Gao X, McKay J, McKay R, Salo Z, Graff JM (2006) Hedgehog signaling plays a conserved role in inhibiting fat formation. Cell Metab 3:25-34

18. Pospisilik JA, Schramek D, Schnidar H et al (2010) Drosophila genome-wide obesity screen reveals hedgehog as a determinant of brown versus white adipose cell fate. Cell 140:148-160

19. Cousin W, Fontaine C, Dani C, Peraldi P (2007) Hedgehog and adipogenesis: fat and fiction. Biochimie 89:1447-1453

20. Teperino R, Amann S, Bayer M et al (2012) Hedgehog partial agonism drives Warburg-like metabolism in muscle and brown fat. Cell 151:414-426

21. Tobin JL, Beales PL (2007) Bardet-Biedl syndrome: beyond the cilium. Pediatr Nephrol 22:926-936

22. Schumacher MA, Donnelly JM, Engevik AC et al (2012) Gastric sonic hedgehog acts as a macrophage chemoattractant during the immune response to helicobacter pylori. Gastroenterology 142: $1150-1159 . e 1156$

23. Kern M, Kosacka J, Hesselbarth N et al (2014) Liver-restricted Repin1 deficiency improves whole-body insulin sensitivity, alters lipid metabolism, and causes secondary changes in adipose tissue in mice. Diabetes 63:3295-3309 
24. Kloting N, Graham TE, Berndt J et al (2007) Serum retinol-binding protein is more highly expressed in visceral than in subcutaneous adipose tissue and is a marker of intra-abdominal fat mass. Cell Metab 6:79-87

25. Hoffmann A, Ebert T, Kloting N et al (2016) Leptin dosedependently decreases atherosclerosis by attenuation of hypercholesterolemia and induction of adiponectin. Biochim Biophys Acta 1862:113-120

26. Matz-Soja M, Aleithe S, Marbach E et al (2014) Hepatic Hedgehog signaling contributes to the regulation of IGF1 and IGFBP1 serum levels. Cell Commun Signal 12:11

27. Berry R, Church CD, Gericke MT, Jeffery E, Colman L, Rodeheffer MS (2014) Imaging of adipose tissue. Methods Enzymol 537:47-73

28. Gericke M, Weyer U, Braune J, Bechmann I, Eilers J (2015) A method for long-term live imaging of tissue macrophages in adipose tissue explants. Am J Physiol Endocrinol Metab 308:E1023-E1033

29. Schindelin J, Arganda-Carreras I, Frise E et al (2012) Fiji: an opensource platform for biological-image analysis. Nat Methods 9:676-682

30. Dong W, Vuletic S, Albers JJ (2009) Differential effects of simvastatin and pravastatin on expression of Alzheimer's disease-related genes in human astrocytes and neuronal cells. J Lipid Res 50:2095-2102

31. Matz-Soja M, Rennert C, Schonefeld K et al (2016) Hedgehog signaling is a potent regulator of liver lipid metabolism and reveals a GLI-code associated with steatosis. Elife 5

32. Todoric J, Strobl B, Jais A et al (2011) Cross-talk between interferongamma and hedgehog signaling regulates adipogenesis. Diabetes 60: 1668-1676

33. Gesellschaft DD (2013) Nationale Versorgungsleitlinien Therapie des Typ-2-Diabetes. Available from http://www.deutsche-diabetesgesellschaft.de/fileadmin/Redakteur/Leitlinien/Evidenzbasierte Leitlinien/NVL_Therapie DM2 lang_Aug_13 geae_Nov_2014.pdf, accessed 12 December 2016 [article in German]

34. Orthgiess J, Gericke M, Immig K et al (2016) Neurons exhibit Lyz2 promoter activity in vivo: Implications for using LysM-Cre mice in myeloid cell research. Eur J Immunol 46:1529-1532

35. Lee YH, Petkova AP, Granneman JG (2013) Identification of an adipogenic niche for adipose tissue remodeling and restoration. Cell Metab 18:355-367
36. Lee YH, Kim SN, Kwon HJ, Maddipati KR, Granneman JG (2016) Adipogenic role of alternatively activated macrophages in betaadrenergic remodeling of white adipose tissue. Am J Physiol Regul Integr Comp Physiol 310:R55-R65

37. Satoh T, Kidoya H, Naito H et al (2013) Critical role of Trib1 in differentiation of tissue-resident M2-like macrophages. Nature 495: 524-528

38. Sekimoto R, Fukuda S, Maeda N et al (2015) Visualized macrophage dynamics and significance of S100A8 in obese fat. Proc Natl Acad Sci U S A 112:E2058-E2066

39. Bolus WR, Gutierrez DA, Kennedy AJ, Anderson-Baucum EK, Hasty AH (2015) CCR2 deficiency leads to increased eosinophils, alternative macrophage activation, and type 2 cytokine expression in adipose tissue. J Leukoc Biol 98:467-477

40. Hussaarts L, Garcia-Tardon N, van Beek L et al (2015) Chronic helminth infection and helminth-derived egg antigens promote adipose tissue M2 macrophages and improve insulin sensitivity in obese mice. FASEB J 29:3027-3039

41. Berisha SZ, Serre D, Schauer P, Kashyap SR, Smith JD (2011) Changes in whole blood gene expression in obese subjects with type 2 diabetes following bariatric surgery: a pilot study. PLoS ONE 6:e16729

42. Porter JA, Young KE, Beachy PA (1996) Cholesterol modification of hedgehog signaling proteins in animal development. Science 274:255-259

43. Wu S, De Luca F (2004) Role of cholesterol in the regulation of growth plate chondrogenesis and longitudinal bone growth. J Biol Chem 279:4642-4647

44. Nakamura M, Ogo A, Yamura M, Yamaguchi Y, Nakashima $\mathrm{H}$ (2014) Metformin suppresses sonic hedgehog expression in pancreatic cancer cells. Anticancer Res 34:1765-1769

45. Fan C, Wang Y, Liu Z et al (2015) Metformin exerts anticancer effects through the inhibition of the Sonic hedgehog signaling pathway in breast cancer. Int J Mol Med 36:204-214

46. Gesta S, Bluher M, Yamamoto Y et al (2006) Evidence for a role of developmental genes in the origin of obesity and body fat distribution. Proc Natl Acad Sci U S A 103:6676-6681 